\title{
"AUT CAESAR, AUT NIHIL!» LA PRESENCIA DE LA ROMANITAS EN EL PRIMER ESCRITO DE HEGEL
}

\author{
«AUT CAESAR, AUT NIHIL!» THE ROLE OF ROMANITAS IN HEGEL'S \\ FIRST WRITING
}

VALERIO ROCCO LOZANO

(Universidad Autónoma de Madrid - Espanha)

\begin{abstract}
Resumen
El rol conceptual desempeñado por el mundo romano en la obra de Hegel, y en concreto en los escritos de juventud, constituye una dimensión necesaria no sólo para comprender su recepción de la cultura clásica y su reacción a determinados acontecimientos de la época, como la Revolución francesa, sino también para explicar su evolución política desde posiciones republicanas y francófilas hasta el pensamiento de madurez. La Unterredung zwischen Dreien, el primer texto de Hegel, influido por las lecturas juveniles de Shakespeare, Schiller y Rousseau, y comprometido con los valores del republicanismo prerrevolucionario, es el más claro ejemplo de la importante presencia de las reflexiones sobre Roma en el autor de la Fenomenología.
\end{abstract}

Palabras-clave: Hegel, Roma, virtus, Revolución francesa, republicanismo, imperio.

\begin{abstract}
The conceptual role played by the Roman World in the Hegelian work, and more precisely in his first writings, is a necessary factor in order to understand not only the Hegel's reception of the classical culture and his reaction to certain events of his time, such as the French Revolution, but also in order to explain his political evolution from republican and Francophile positions to his mature thinking. The Unterredung zwischen Dreien, the very first text of Hegel, influenced by Shakespeare, Schiller and Rousseau, and committed to the values of pre-revolutionary republicanism, is the most evident example of the important presence of the reflection upon Rome in the Fenomenology's author.
\end{abstract}

Key-words: Hegel, Rome, virtus, French Revolution, republicanism, empire.

La presencia de Roma en Hegel ha sido olvidada. Esta es la conclusión a la que se llega comparando la abundancia de páginas y la relevancia de las afirmaciones dedicadas por el filósofo suabo al Imperio romano, su cultura, su religión, su filosofía, con la escasez de estudios de especialistas sobre este aspecto. De hecho, no sólo carecemos de libros o artículos que traten monográficamente de la presencia y el papel de Roma en el pensamiento hegeliano ${ }^{1}$, sino que este olvido contagia incluso a los numerosos Hegel-Handbücher: en ninguno de estos diccionarios dedicados al autor de la Fenomenología existe una voz independiente para "Roma" o "Imperio Romano", y sólo en el de Michael Inwood encontramos una referencia al concepto "Rome, Romans" en el índice analítico al final de la obra. Si se compara esta falta de estudios con las numerosas y a menudo bellas páginas que los Hegel-Kenner han dedicado a Grecia, la cuestión se hace aún más sospechosa y alarmante: el mundo griego y el romano ocupan aproximadamente el mismo número de páginas en las Lecciones de Filosofía de la Historia, pero mientras que sobre el Weltreich que supone la bella infancia del género humano han corrido ríos de tinta ${ }^{3}$, sobre la varonil edad del mundo romano no se ha escrito casi nada. Esta asimetría, en el caso romano, entre fuentes primarias y bibliografía 
secundaria tiene causas profundas, ligadas sobre todo a una innegable grecomanía del ambiente intelectual alemán desde Hegel hasta nuestros días, que no es este el momento de analizar en profundidad. Sin embargo, esta disparidad, este vacío de la interpretación, debe suponer un acicate a la investigación, encaminada al estudio sistemático de una porción enorme del entero sistema hegeliano: el papel que las manifestaciones artísticas, religiosas, literarias, políticas y jurídicas del mundo romano juegan en la filosofía hegeliana. La enorme cantidad de material casi virgen que se esconde en la obra de uno de los pensadores más estudiados de la historia de la filosofía es ya de por sí una razón suficiente para intentar pensar, parafreseando a Heidegger, qué significan las palabras "Hegel y los romanos".

Sin embargo, esta carencia de estudios específicos no supone la única razón para emprender esta ardua tarea: la importancia de la investigación cobra una dimensión esencial para la comprensión de la estructura y la evolución del pensamiento de Hegel. De hecho, es llamativo su cambio de actitud acerca de Roma en las distintas fases de su filosofía: se pasa de un sincero respeto, a veces teñido de manifiesta admiración, hacia esta época de la Historia Universal, en los primeros escritos juveniles, hasta las duras críticas contra la sociedad y la política romanas de la etapa berlinesa; el Imperio Romano pasará a ser pintado (con esa inusitada dureza que tanto extrañaba a Ortega ${ }^{4}$ ) con los rasgos de la irracionalidad, la injusticia y el desorden. La comprensión de este tránsito tan llamativo se hace necesaria en el marco de la tarea polifacética de destruir la imagen estereotipada de un Hegel bifronte, o mejor dicho de dos filósofos distintos, el joven revolucionario francófilo y el maduro estatalista filoprusiano; la interpretación de Hegel debe asumir el denuedo conceptual de desentrañar las causas y los modos de la evolución de su pensamiento para hallar la continuidad en su obra ${ }^{5}$, reinterpretando las aparentes fracturas como virajes, y analizando las confrontaciones internas a su pensamiento a la luz de los acontecimientos y las influencias que marcaron cada época de su vida. En este sentido, la pregunta por el papel jugado por Roma en el sistema hegeliano nos conduce al necesario análisis de las principales lecturas (Gibbon, Montesquieu, Rousseau, Schiller, Herder, etc.) que contribuyeron a forjar en el filósofo una determinada imagen de esa lejana realidad pasada. Al mismo tiempo, nos compele al análisis de los acontecimientos que, durante la vida de Hegel, y especialmente en su etapa de juventud, pudieron condicionar su juicio sobre la antigua Roma.

El análisis de los textos y de las informaciones biográficas del filósofo nos indican que fue sobre todo la influencia de la Revolución, y sus consecuencias culturales, más que políticas, en el ambiente germánico, lo que nos permite explicar el viraje de Hegel desde la inicial admiración hacia Roma hasta el distanciamiento ya evidente en la Fenomenología o en los Principios de Filosofía del Derecho. El tránsito se condensa en el período de juventud, en los años de Stuttgart, Tubinga, Berna y Frankfurt, mientras que en Jena encontramos ya plenamente fijado el juicio crítico y fundamentalmente negativo que permanecerá hasta el final de su vida. Por esta razón, esta época inicial de formación y consolidación del pensamiento hegeliano adquiere una importancia especial en la 
comprensión de la temática que nos ocupa. De hecho, y para adentrarnos en la temática específica de este artículo, la etapa juvenil se muestra decisiva en este asunto. De hecho, y esta es una ulterior, poderosísima razón para estudiar el tema de Roma en Hegel, el primerísimo escrito que se conserva de nuestro (por aquél entonces incipiente) pensador está precisamente impregnado, en su forma y en su contenido, de los temas de la Romanitas.

Si se lanza una rápida mirada hacia los tres textos principales de la época de Stuttgart (Über die Religion der Griecher und Römer ${ }^{6}$, de 1787, Über einige charakterische Unterschiede der alten Dichter [von der neueren] $]^{7}$, de 1788, y Über einige Vorteile, welche uns die Lekture der alten klassischen griechischen und römischen Schrifsteller gewährt ${ }^{8}$, del mismo año), que se enlazan temática y evolutivamente entre sí, se puede leer en ellos una imagen de sustancial admiración y entusiasmo del joven Hegel hacia la Antigüedad clásica; mientras que en los primeros dos el mundo helénico y el romano quedan sustancialmente indefinidos, en el último, el que más claramente distingue la cultura griega de la romana, se puede afirmar que el estudiante del Gymnasium Illustre concede a la primera una primacía absoluta en cuanto a aspectos estéticos ${ }^{9}$, mientras que respecto al papel de los historiadores y a la intervención práctica de la filosofía, según Hegel destaca principalmente el importante papel desempeñado por Roma ${ }^{10}$. Tendríamos por lo tanto, en la fase inicial del pensamiento hegeliano, una incipiente asimetría en la alabanza a Grecia y Roma: la primera es la indiscutible referencia artística y literaria, la segunda constituiría el principal modelo histórico-político

Esta afirmación sería difícil de probar apoyándose tan sólo en las escuetas frases de Über einige Vorteile, es decir, si no se conservara ningún escrito de temática estrictamente política de la época de Stuttgart; sin embargo, afortunadamente Hoffmeister ha recogido en su compendio una obra, fechada en 1785, cuando Hegel contaba tan sólo con quince años. Se trata de la Unterredung zwischen Dreien, texto de gran valor simbólico por tratarse, como se ha adelantado, del primero, de los que escribió Hegel, que ha llegado hasta nosotros; por lo tanto, en términos meramente cronológicos, es anterior a los tres que se han citado supra. Sin embargo, su temática histórica y política lo acerca mucho más a escritos de la época de Berna como los Fragmentos republicanos, al mismo tiempo que su estilo literario lo conecta con obras, también posteriores, como la Vida de Jesús. El tema del escrito es una conversación entre Octavio, Antonio y Lépido acerca de sus planes para hacerse con el poder en Roma tras el asesinato de César a manos de los conjurados. Ripalda ha destacado que la decisión de escribir sobre esta temática se debió a la fuerte presencia de autores clásicos, en este caso latinos, que abordaban asuntos genuinamente políticos. Este "ambiente escolar humanista" 11 del que habla el autor de La nación dividida es exactamente el mismo del que había hablado Desmoulins a la hora de juzgar la enorme influencia de los clásicos en la forja de ideas políticas en los revolucionarios franceses ${ }^{12}$. También en el Gymnasium de Stuttgart "la temática política no era descuidada, pero su enfoque era exclusivamente individual (lo cual, de paso, modernizaba decisivamente la Antigüedad); la Entrevista [sic!] entre tres es típica a este respecto" 13 . 
Fascinado por las ideas de la libertas republicana y de la virtus estoica aprendidas en sus interminables clases sobre la historia y la literatura romanas, el joven Hegel escribe un texto impetuoso, lleno de entusiasmo y de amor hacia estas nociones. Sin embargo, no se trata ni mucho menos de un planteamiento ingenuo, a pesar de lo que podría pensarse por la edad del autor: la prueba de ello es el medio indirecto, sub contrario, a través del cual Hegel elogia la libertad de la República romana. De hecho, en vez de glorificar directamente a sus defensores - especialmente a Bruto, según lo que había sido costumbre de la época ${ }^{14}$, Hegel narra las ideas y los proyectos de los enemigos de la libertas, y los describe con tonos tan negativos que la simpatía del lector hacia las ideas republicanas que éstos pretenden destruir es inmediata. Se trata pues, de un procedimiento indirecto. Las dudas de Octavio ante los planes de Antonio de volver a instaurar un poder absoluto tras el regicidio, sirven de hecho para aclarar, de forma indirecta, que el régimen republicano estaba marcado por una libertad a la que los romanos no renunciarán fácilmente: “¿Podrán los libres romanos explicarse cabalmente nuestro señorío? ¿Permanecerán en calma ante esta situación Bruto, Casio, y aquellos otros que ayudaron en la muerte del noble César? Y Sexto Pompeyo, ¿se dejará apaciguar?”"15. Al formular el futuro Augusto otra duda, expresando el sentir general del pueblo de Roma más que su propia opinión, tiene que reconocer la gran talla moral de sus adversarios, los cesaricidas: "mas un Bruto, o un Casio, se encuentran bien por encima de la plebeya esfera" ${ }^{16}$. Este pasaje permite a Hegel ensalzar, esta vez de manera directa, a los héroes de la libertas republicana.

Al contrario, los futuros triúmviros son pintados en el texto como abyectos usurpadores del poder popular; de hecho, de cara al pueblo, muestran un desprecio aristocrático al creer que pueden corromperlo con la clásica fórmula de panem et circenses: "sucede, en el caso de la baja plebe, con unas pocas palabras, algo de trigo y espectáculos públicos" ${ }^{17}$. Al mismo tiempo, entre ellos, carecen de esa virtus fundamental que es la lealtad: al mismo tiempo que se alían para derrocar el régimen republicano, planean en secreto eliminarse entre ellos para hacerse con el poder único. Primero Antonio manifiesta a Octavio su intención de librarse de Lépido en cuanto alcancen el poder: “¿Acaso deberíamos permitir que esta cabeza estéril (unfruchtbaren Kopf) participe algún día de la dominación del mundo?" ${ }^{18}$. Frente a esta sugerencia, Octavio se muestra reticente, declarando su respeto hacia Lépido como soldado. ¿Encontramos aquí una relativa salvación del futuro princeps, quizás una implícita admiración de Hegel a este personaje tan majestuoso, a pesar de sus acciones liberticidas ${ }^{19}$ ? De ninguna manera.

De hecho, el estudiante adolescente sabe muy bien qué valores y personajes debe atacar, y al final del texto Octavio es representado como el más despreciable de los tres: de hecho, en un intenso y dramático monólogo interior, el futuro Augusto muestra que su defensa de Lépido era una trampa para que Antonio se confíe y no sospeche de él cuando le elimine, y decida hacerse con el poder absoluto: "La memez iba en cabeza, y tras ella la arrogancia. Lo que Antonio dijo sobre Lépido no era falso. Mas Antonio es orgulloso, cruel, ambicioso y lascivo. Si vencemos a nuestros enemigos y Lépido es apartado, Antonio, orgulloso de sus hazañas y experiencia, querrá burlarme 
a su voluntad como a un jovenzuelo. Pero no encontrará en mí a ningún Lépido. Mi cuello no ha conocido amo, y no está acostumbrado a arrimarse al cobijo de un dominador de mirada altiva. Dejaré que retoce en sus lascivias y me mantendré pacientemente al margen. Cuando sus fuerzas físicas y anímicas estén adormecidas, cuando se encuentre desprevenido, sólo entonces, levantaré mi frente, le dejaré ver mi propia grandeza, y entonces...aut Caesar, aut nihil. O bien deberá postrarse ante mí en el polvo, o bien preferiré la muerte antes que una vida ignominiosa"20. Como se ve, el lenguaje típicamente republicano de insumisión ante la esclavitud es aquí pervertido por el futuro Augusto: su cuello jamás doblegado ante un amo (en virtud de la libertad reinante en la República) no se humillará ante los propósitos de omnímoda dominación de Antonio. Pero el fin de esta oposición no es la preservación de la libera respublica Romanorum, sino el sueño de convertirse él mismo en princeps, o de perecer en el intento: o César, o nada. La conspiración entre los tres se revela carente de todo fundamento ideológico, de cualquier legitimación política, y es abiertamente condenada como una lucha por el poder personal, en la que la principal víctima es la libertad de una República profundamente admirada por el joven Hegel.

Una vez resumido brevemente el contenido del texto, cabe preguntarse por las influencias que lo inspiran. La primera de ellas y quizá la más conocida, es la de Friedrich Schiller, y concretamente una obra aparentemente alejada de la temática romana, el Fiesco, ambientado como se sabe en la Génova dominada por la familia Doria. Este drama fue leído por Hegel en el Gymnasium por un hecho nimio, que no tiene nada que ver con su temática ni con el hecho de que lleve como subtítulo "Ein republikanischer Trauerspiel"21: "se da el caso interesante de que el Fiesco estuviera dedicado a un profesor de Hegel, Jacob Friederich Abel. Schiller había estudiado su bachiller en Stuttgart, donde Abel fue su profesor preferido y él su discípulo predilecto ${ }^{22}$. Esta circunstancia pudo tener parte en que Hegel trabajase detenidamente una obra de Schiller que apenas tuvo resonancia. Abel, que sería profesor de Hegel otra vez en Tubinga, tenía una relación bastante estrecha con éste desde Stuttgart" ${ }^{23}$. Pues bien, una vez aclaradas las razones de la lectura de esta obra, podemos preguntarnos en qué sentido influyó la historia del Conde de Lavagna, ambientada en el siglo XVI, en el escrito de Hegel sobre los turbios momentos de paso de la República al Principado en la antigua Roma.

En primer lugar, hay que notar la similitud del tema, es decir, la conjura de un grupo de republicanos para derrocar en un caso a la familia Doria, en la otra el régimen legal republicano. Sin embargo, es preciso reconocer desde el principio que el texto de Schiller es muy ambiguo desde el punto de vista político: los tiranos (Andrea y Giannettino) están rodeados de un aura heroica de la que carecen los conspiradores, que en cambio son presentados como malvados, en el caso de Sacco y Calcagno, u orgullosos, como ocurre con el propio Fiesco. Como comenta Ripalda "un romántico prefiere un alma grande y noble (en el doble sentido de la palabra) al pueblo, incapaz de vivir más que representativamente y como un esclavo" 24 .

La segunda y más importante conexión que esta obra de teatro schilleriana tiene con la Unterredung hegeliana son las continuas referencias a Roma, ya desde la cita de Salustio sobre 
Catilina que abre la Vorrede: "nam id facinus in primis ego memorabile exsistimo sceleri atque periculi novitate"25 ("considero este delito en primer lugar por la singularidad de la maldad y del peligro"). La jerga republicana de los conjurados renacentistas es la misma que leemos en las obras de los escritores y filósofos políticos romanos; este hecho es muy importante por sus similitudes con el léxico empleado durante la Revolución francesa: según muchos estudiosos, las referencias de los revolucionarios a la antigua Roma se debían a que prácticamente no conocían ningún otro ejemplo de retórica y terminología política republicana. Pues bien, Schiller, al comentar una conjura del siglo XVI, tiene el mismo problema, por lo que recurre constantemente a tópicos de la literatura latina. En palabras de Ripalda, "el Fiesco de Schiller, a pesar de su indecisión política, y en parte también por ella, se atropella en tiradas llenas de «república»y «republicanos», «tiranía»y «tiranos», «libertad», «virtud». El modelo ideal en el que todo este vocabulario entusiasta se mide es la Roma preimperial, auténtica y «virtuosa». El exergo es una cita de Salustio sobre Catalina. Virginia y Appius Claudius, Octavio, Bruto, Porcia, son conjurados en los momentos decisivos"26. Por lo tanto, principalmente por esta razón, el Fiesco de Schiller debe considerarse como un elemento importantísimo de las influencias del joven Hegel a la hora de redactar la Unterredung.

Sin embargo, existen otras fuentes aún más determinantes sobre todo en cuanto al contenido, a la temática elegida para este escrito, fundamentalmente Plutarco y el tercer acto del Julio César shakespeariano. Hegel había leído a Shakespeare desde muy joven, gracias a la influencia del profesor Löffler en el Gymnasium de Stuttgart. Al final del recordatorio de este profesor con ocasión de su fallecimiento, Hegel anota: “debo añadir que en 1778 me regaló 18 tomos de los dramas de Shakespeare"27. Ya desde la edad de ocho años el fututo autor de la Fenomenología se había apasionado con las obras (en la versión alemana de Erschenburg ${ }^{28}$ ) del dramaturgo inglés, que había sido casi divinizado por personajes tan influyentes como Goethe, Wieland, Herder o Lessing $^{29}$. Seguramente el Julio César tuvo que ser uno de los dramas que más impresionaran a Hegel: en esta obra, a su vez influida por Plutarco y Lucano ${ }^{30}$, se encuentran muchos elementos simbólicos que influirán profundamente en el ideario republicano y revolucionario, como por ejemplo la idea de una continuidad espiritual entre los dos Brutos ${ }^{31}$. El impacto que tuvo que causarle a Hegel fue enorme; de hecho, incluso en puntos irrelevantes de la obra del joven estudiante de Stuttgart se encuentran rastros de este drama shakespeariano. Un ejemplo evidente de este hecho se encuentra en un pasaje perteneciente a un escrito que ha hemos citado, Über die Religion; en él Hegel decía que "todavía en nuestros días se predice el fallecimiento de un Rey a partir de un cometa" 32 . Pues bien, en la Escena Segunda del Acto Segundo del Julio César había escrito Shakespeare: "no es al morir los mendigos cuando se ve aparecer a los cometas; pero los cielos mismos se inflaman para anunciar la muerte de los príncipes" 33 .

La similitud de la Unterredung con algunos pasajes del drama shakespeariano es verdaderamente sorprendente, sobre todo en el caso de la Primera Escena del Acto Cuarto; en estas dos páginas encontramos una conversación entre los mismos protagonistas que elegirá Hegel: Octavio, 
Antonio y Lépido. También se puede leer el desprecio de los primeros dos hacia el último, con palabras y expresiones casi idénticas a las de la Unterredung: "éste es un pobre hombre sin mérito que sólo vale para hacer recados. ¿Es conveniente que, dividido el mundo en tres partes, venga a ser él uno de los tres que lo dominen? [...] Es un espíritu estéril que se alimenta con objetos, artes e imitaciones, manoseadas por otros hombres y caídas en desuso, pero que para él son moda nueva" 34 . También se encuentra en esta escena la defensa de Octavio ("es un bravo y experto soldado"35) que veíamos en Hegel, así como una sutil indicación de las futuras disputas internas en el triunvirato: "me temo que algunos de los que nos sonríen tienen en su corazón abismos de maldad" 36 . Por lo tanto, queda claro que muchos de los puntos temáticos abordados por Hegel se encuentran presentes en el Julio César shakespeariano.

Pero entonces, cabe preguntarse si la obra de Hegel no pierde por ello mucho de su valor filosófico, al tratarse de una mera imitación de dos grandes dramas, el Fiesco y el Julio César, por parte de un quinceañero fascinado por historias de intrigas y conspiraciones. ¿Cómo puede intentar sacarse alguna conclusión teóricamente relevante de esta composición escolar y mimética, donde la originalidad está prácticamente ausente? A esta objeción se puede contestar diciendo que, aunque se concediera que efectivamente Hegel no hace sino combinar temas schillerianos y shakepearianos sin aportar nada original, este documento nos habría servido al menos para reconstruir influencias fundamentales en la visión sobre Roma del período de Stuttgart. Sin embargo, si se analiza detalladamente el texto de la Unterredung se puede ver que existe una diferencia fundamental con respecto tanto al Fiesco como al Julio César, y que señala la originalidad de la postura del Hegel de estos años. Tanto Shakespeare como Schiller, en sus obras, no habían tomado partido por ninguno de los dos bandos: en el Julio César se encuentran elogios y panegíricos igualmente entusiastas tanto hacia Bruto como hacia el personaje que da nombre a la obra. En el caso del Fiesco la balanza se inclinaba incluso, como hemos visto, del lado de los tiranos, pintados con un aura de grandeza y sublimidad completamente ausente entre los conjurados. Pues bien, Hegel, casi como si quisiera hacer justicia y alterar el equilibrio de estas dos obras determinantes de su juventud, toma una postura claramente favorable a los conjurados republicanos, al mismo tiempo que destruye ese velo de grandeza y nobleza que podían tener los tres futuros triumviros, y sobre todo Octavio, en la obra de Shakespeare: de hecho, a lo largo de todo el Julio César se subraya que la venganza de los herederos del asesinado está moralmente justificada. Además, la frase conclusiva de esta obra es para el futuro Emperador, que se muestra pius y clemente hacia los restos sin vida de Bruto: "tratémosle conforme a sus virtudes, con todo respeto y solemnidad en sus funerales. Sus restos descansarán esta noche en mi tienda como los de un soldado con los debidos honores" ${ }^{37}$. En cambio, como hemos visto, Hegel acentúa en su texto el desprecio que los tres personajes tienen hacia Bruto, y en el monólogo final de Octavio presenta a este último como un político orgulloso, cínico y despiadado, carente de toda motivación ideológica que no sea la de conseguir un poder personal y absoluto. Además, si Shakespeare había simplemente aludido a las futuras luchas entre los tres 
vencedores de la batalla de Filipos, Hegel hace de estas disensiones el núcleo de su texto, para acentuar mediante proyectos de traiciones y venganzas (temáticamente presentes en el Fiesco) el carácter abyecto de los derrocadores de la República romana.

Por lo tanto, lejos de cualquier indiferencia, Hegel toma partido por el sector republicano sin condenar en ningún momento el cesaricidio; en esta actitud se puede ver su admiración por la forma política de la Roma pre-imperial ${ }^{38}$ y su desprecio hacia su posterior corrupción en las formas del Principado y el Dominado. El amor por la virtud y la libertad propias del estoicismo republicano, que Hegel sentía la necesidad de defender al "corregir" a Shakespeare y a Schiller en la Unterredung, tenía que provenir de una fuente muy influyente, probablemente la más importante que se encuentra en los escritos de juventud, por lo menos hasta Frankfurt. Se trata naturalmente de Jean-Jacques Rousseau, el difusor, en toda Europa, de esa admiración sin límites hacia Roma y Esparta que, como se sabe, tanto influyó en los revolucionarios.

Es una vexata quaestio entre los estudiosos de Hegel el momento en el que éste comenzó a leer directamente al pensador ginebrino. Numerosos testimonios relatan que en los primeros años de Tubinga "estaba siempre leyendo a Rousseau" ${ }^{39}$. Sin embargo, sobre el período de Stuttgart, las opiniones son contrastantes: muchos creen que sólo tenía conocimiento de algunas temáticas rousseaunianas a través de la lectura del Neuer Emil de Feder, del que se ha conservado una extensa recensión precisamente del año $1785^{40}$, pero que "queda en la oscuridad si había leído directamente a Rousseau" ${ }^{41}$. Para otros intérpretes, además de conocer el contenido del Emilio y de otros escritos rousseaunianos a partir de Feder, Hegel habría leído en Stuttgart los primeros seis libros de las Confesiones, de las que al parecer realizó un Exzerpt que no se ha conservado ${ }^{42}$. De esta opinión es Ripalda, que se apoya en Rosenkranz, así como en una llamativa correspondencia temática y lingüística entre una entrada del diario de 1785 y un pasaje del libro tercero de la obra de Rousseau ${ }^{43}$. Otros intérpretes, aún más arriesgados, ven en algunas obras de Stuttgart resonancias incluso de otros libros, como es el caso de los Discursos y del Contrato social: así lo opina Tassi en el caso concreto de Sobre algunas diferencias ${ }^{44}$. Sin tomar partido por ninguna interpretación en especial, hay que coincidir con la mayoría de los intérpretes en que las principales ideas políticas de Rousseau eran bien conocidas por Hege ${ }^{45}$ ya en la época de Stuttgart, y que a medida que entre este período y el de Tubinga su conocimiento de las obras del pensador ginebrino aumentaba, también se consolidaba esa imagen de la Roma republicana que vemos esbozada en la Unterredung.

Sin embargo, ¿cuál es, más precisamente, esta imagen de Roma que Hegel lee en los escritos de Rousseau? ¿Qué rasgos y peculiaridades caracterizan a la libera res publica Romanorum en estas obras que tanta influencia tuvieron sobre el primero en la época de juventud? En primer lugar, hay que repetir algo que ya indicábamos más arriba, es decir, que en el Contrato social la visión de Roma está fuertemente vinculada a la de Esparta bajo el signo común de un estocismo libre, sobrio y viril ${ }^{46}$. Es importante destacar que esta conexión implica también una contraposición con Atenas, situada en un plano inferior, y caracterizada por elementos artísticos y retóricos, mientras que la 
pareja Roma-Esparta está marcada por una virtud activa, práctica y marcial. Es en este sentido en el que se explica la famosa contraposición entre "bien decir y bien obrar" en el Discurso sobre las ciencias y las artes: "he ahí la verdadera filosofía, sepamos contentarnos con ella; y, sin envidiar la gloria de esos hombres célebres que se inmortalizan en la república de las letras, tratemos de poner entre ellos y nosotros esa gloriosa distinción que se observaba antaño entre dos grandes pueblos: que uno sabía bien decir, y el otro, bien obrar" ${ }^{47}$. Estos dos pueblos son, como ya había escrito Montaigne en el capítulo XXV del libro I de los Ensayos, Esparta y Atenas, la primera llena de "retóricos, pintores y músicos", mientras que la segunda producía "legisladores, magistrados y caudillos"48. Naturalmente las simpatías de Rousseau están del lado de lacedemonios y romanos, y en contra de la corrupción que la influencia ateniense introdujo en el Imperio, contribuyendo a su decadencia ${ }^{49}$ : "que otras manos se ilustren con talentos vanos; el único talento digno de Roma es el de conquistar el mundo y hacer reinar en él la virtud"50. Evidentemente Hegel no comparte la polémica de Rousseau frente a la cultura, pero su distinción entre una Grecia superficial y dedicada al conocimiento teórico por un lado y una pareja Roma-Esparta caracterizada por la primacía de lo práctico, es fundamental en el joven Hegel. Como ya se ha dicho, especialmente en Sobre algunas ventajas, Grecia es la patria del refinamiento y del arte, mientras que Roma es el modelo para la acciones políticas y para el relato (histórico) de las mismas.

En el Discurso sobre las ciencias y las artes de Rousseau, Hegel encuentra también un elogio de la sencillez y de la inocencia de la Roma pre-imperial, pintada con esos rasgos de pueblo "originario" que también por influencia de Garve encontramos en los escritos de los años 1787 y 1788: así, Rousseau insiste en el Discours en incluir a los romanos de los orígenes en el "pequeño número de pueblos que, preservados de ese contagio de los vanos conocimientos, han hecho con sus virtudes su propia felicidad y el ejemplo de las demás naciones" ${ }^{\circ 1}$. Además de la Roma republicana conforman este selecto $c l u b$ los primeros persas, los escitas, los espartanos y...los germanos, "cuya simplicidad, inocencia y virtudes pintó con alivio una pluma harta de trazar los crímenes y las negruras de un pueblo instruido, opulento y voluptuoso" ${ }^{52}$. La referencia es evidentemente a Tácito, que más tarde será abundantemente utilizado por los teutómanos precisamente por sus elogios desde (y contra) la decadente Roma a los sobrios germanos.

Lo que es fundamental entender, tanto en Rousseau como en el Hegel de estos primeros años, es que hay más puntos en común entre los rudos y fieros germanos y la Roma republicana y estoica que entre ésta y el régimen despótico e imperial que la derrocó. La tesis historiogáfica reciente, que intenta acertadamente subrayar los puntos de continuidad entre la fase Republicana y la del Principatus, era desconocida a estos dos filósofos, que en cambio insistían en la fractura política y cultural que había representado justamente la toma de poder de ese Augusto tan denostado por Hegel en la Unterredung. Para éste y para Rousseau lo que hermana dos pueblos o dos espíritus no es su nacionalidad o su cultura, sino única y exclusivamente la virtud; y según el Contrato social el lugar por excelencia de cultivo de la virtud es Roma: "cada pueblo encierra 
en sí alguna causa que lo ordena de una manera particular y hace su legislación idónea sólo para él. Así es como antaño los hebreos y recientemente los árabes han tenido por principal objeto la religión, los atenienses las letras, Cartago y Tiro el comercio, Rodas la marina, Esparta la guerra y Roma la virtud"53. A partir de este ideal de virtus especificamente romano se construye una línea política de matriz rousseauniana que acerca mucho al Hegel de estos años a los contemporáneos discursos de los revolucionarios franceses ${ }^{54}$. En este sentido, estudiar la el papel conceptual jugado por el mundo romano en estas obras juveniles resulta, además de apasionante, imprescindible para la comprensión del incipiente pensamiento político de un gran pensador sumergido en el contexto de la mayor Begebenheit de su época. 


\section{Referências}

BONACINA, G. Hegel, il mondo romano e la storiografia. Rapporti agrari, diritto, cristianesimo e tardo antico, Florencia: La Nuova Italia, 1991.

D’HONDT, J. Hegel. Barcelona: Tusquets, 2002. . Hegel secreto. Buenos Aires: Corregidor, 1976.

DUICHIN, M. Introduzione a D’Hondt, J. In.: Hegel segreto. Milán: Guerini e Associati, 1989.

DUQUE, F. Historia de la filosofia moderna. La era de la crítica. Madrid: Akal, 1998.

DÜSING, K. Hegel e l'antichità classica. Nápoles: La Città del Sole, 2001.

ERLE, G. Logos e natura: aspetti della critica di Hegel al dover essere. In.: Fenomenologia e Società. $\mathrm{n}^{\mathrm{o}}$. $2 / 2009$.

GiARdinA, A.; VAUCHEZ, A. Il Mito di Roma da Carlo Magno a Mussolini. Roma-Bari: Laterza, 2000.

HARRIS, H. S. Hegel's Development. Oxford: Oxford University Press, 1972.

HEGEL, G. W. F. Frühe Exzerpte, in Gesammelte Werke. 3, Hamburgo: Felix Meiner Verlag, 1991. . Frühe Schriften I, in Gesammelte Werke, 1, Hamburgo: Félix Meiner Verlag, 1989.

HOFFMEISTER, J. (Hrsg.) Dokumente zu Hegels Entwicklung. Stuttgart: Fromman-Holzboog, 1974.

ILLETTERATI, L.; MORETTO, A. (Eds.) Hegel, Heidegger e la questione della Romanitas. Roma: Edizioni di Storia e Letteratura, 2004.

INWOOD, M. A Hegel Dictionary Oxford-Malden: Blackwell, 1999, p. 345.

MACOR, L. A. Il giro fangoso dell'umana destinazione. Friedrich Schiller tra l'illuminismo e il criticismo. Pisa: ETS, 2008.

NARDUCCI, E. Lucano: Un'epica contro l'impero. Roma-Bari: Laterza, 2002.

ORTEGA Y GASSET, J. Hegel: Notas de trabajo. Madrid: Abada, 2007.

PINKARD, T. Hegel. Madrid: Acento, 2001.

POZZO, R. Hegel: 'Introductio in philosophiam'. Florencia: La Nuova Italia, 1989.

RIPALDA, J. M. El fin del clasicismo: A vueltas con Hegel. Madrid: Trotta, 1992. . La nación dividida. México: FCE, 1978.

ROCCO, V. De la cuádruple fuga de Eleusis. Despalabro. In: Ensayos de Humanidades. n. III, 2009.

ROUSSEAU, J.-J. Del Contrato Social. Discursos. Madrid: Alianza, 2001.

RÜHLE, V. En los laberintos del autoconocimiento: el Sturm und Drang y la Ilustración alemana. Madrid: Akal, 1997.

SCHILLER, F. Die Verschwörung des Fiesco zu Genua. Stuttgart: Philipp Reclam, 2006.

SHAKESPEARE, W. Macbeth, Otelo y Julio César. Madrid: Edaf, 2006.

SICHIROLLO, L. Sur Hegel et le monde grec. In.: D’Hondt, J.(Ed.) Hegel et la pensée grecque, París: PUF, 1974.

TASSI, A. G. W. F. Hegel e gli anni di Stuttgart e Tübingen Milán: Guerini, 1996. 


\section{Notas}

${ }^{1}$ La única excepción es el libro de Bonacina, G., Hegel, il mondo romano e la storiografia. Rapporti agrari, diritto, cristianesimo e tardo antico, Florencia: La Nuova Italia, 1991, donde sin embargo no existe una consideración sistemática del papel de Roma, y la atención del autor se concentra en aspectos muchas veces secundarios. La mejor publicación existente hasta el momento sobre el tema de Roma en Hegel tiene la característica de ser en cierto modo "compartida"; de hecho, aborda el papel conceptual de Roma conjuntamente en las producción de Hegel y Heidegger: cfr. Illetterati, L., Moretto, A., (Eds.), Hegel, Heidegger e la questione della Romanitas, Roma: Edizioni di Storia e Letteratura, 2004.

${ }^{2}$ Cfr. Inwood, M., A Hegel Dictionary, Oxford-Malden: Blackwell, 1999, p. 345.

${ }^{3}$ Una revisión del estado de la cuestión sobre el tema de "Hegel y los griegos", lamentablemente sólo hasta 1974, se encuentra en Sichirollo, L., «Sur Hegel et le monde grec», D’Hondt, J., (Ed.), Hegel et la pensée grecque, París: PUF, 1974, págs. 159-183. El ejemplo más evidente de la absoluta falta de interés por parte de los estudiosos de Hegel sobre el mundo romano es el de Düsing, K., Hegel e l'antichità classica, Nápoles: La Città del Sole, 2001, donde se reduce sin más "lo clásico" al mundo griego.

${ }^{4}$ Cfr. Ortega y Gasset, J., Hegel. Notas de trabajo, Madrid: Abada, 2007, pp. 148-149: “entre las manos apenas si encuentra Hegel más que irracionalidad: el espíritu griego o romano que con placer manosea de pronto se insubordina, se encabrita, empieza a hacer disparates y deja de ser espíritu. Así «los emperadores representan el haberse puesto fuera de sí el espíritu». Es graciosa la ingenuidad de la frase: este estar fuera de sí el espíritu (que es la definición de la naturaleza) significa aquí más que irracionalidad, significa demencia y frenesí. Y esa demencia es nada menos que el imperio romano -seguramente lo más importante que hasta ahora ha habido en la historia. (Véase lo de las «Privatpersonen» como gusanos -frase barroca). Cítese toda esta descripción de la putrefacción romana. Es curioso que para Hegel de pronto la vida histórica se vacía de realidad (siendo así que toda vida es positiva, salvo suicidio). Entonces define por negaciones: así el imperio es «la falta de centro político y ético», de orden, de justicia... ¡Y sin embargo, la positividad de la vida segura! Pero Hegel no la prende".

${ }^{5}$ Esta tarea ha sido asumida, entre otros, por Jacques D’Hondt, cuya contribución a la interpretación de los escritos de juventud de Hegel sigue siendo determinante, más allá de algunos aspectos discutibles de su posición; como escribe Marco Duichin en la Introducción a la edición italiana de la más importante de las obras de estudioso francés, "grazie alla recerca di D'Hondt si delinea cosí una concreta liaison fra quel giovane Hegel -sconosciuto ai suoi futuri seguaci di sinistra- anticristiano e filo-rivoluzionario [...]- e lo Hegel berlinese celebrado da Heine, che continuava a professare in privato, dietro una maschera ortodossa e rispettabile, quegli stessi ideali giovanili» (Duichin, M., «Introduzione» a D’Hondt, J., Hegel segreto, Milán: Guerini e Associati, 1989, pp. 31-32). También Pozzo, R., Hegel: 'Introductio in philosophiam', Florencia: La Nuova Italia, 1989, pp. 186-187, señala que “il momento della transizione, nell'autunno 1800, porta con sé tali e tanti elementi del passato da lasciar rintracciare diversi motivi di continuità tra due posizioni filosofiche, quali quelle di Francoforte e di Jena, che eppure sono assai diverse tra loro".

${ }^{6}$ Cfr. Hoffmeister, J. (Hrsg.), Dokumente zu Hegels Entwicklung, Stuttgart: Fromman-Holzboog, 1974, p.. 43.

${ }^{7}$ Cfr. Hoffmeister, J., op. cit., pp. 48-51

${ }^{8}$ Cfr. Hoffmeister, J., op. cit., pp. 169-172.

${ }^{9}$ Cfr. Hoffmeister, J., op. cit., p. 170: “die Griechen- die hier vorzüglich gemeint sind, da die Römischen Schriften, ohne Rücksicht auf den Inhalt betrachtet, meistens nur Nachahmungen jener sind".

${ }^{10} \mathrm{Cfr}$. ibidem. En general, señala Hegel, la lectura de los pensadores antiguos es una fuente importantísima de adquisición de conceptos, y por ello es una muy buena preparación para la filosofía. De hecho, en los antiguos filósofos encontramos la semilla y las primeras bases de problemas que han recibido en tiempos recientes una más clara formulación. A continuación viene lo más importante: Hegel aclara que, especialmente en lo que afecta a la especulación sobre la parte práctica del saber ("den praktischen Teil der Weltweisheit"), las controversias entre los antiguos filósofos son de gran importancia, por lo menos para emprender más fácilmente el camino que conduce hacia la verdad. En este pasaje conclusivo, que pone el acento en el papel activo y transformador de la sabiduría del filósofo, Tassi, A., $G$. $W$. F. Hegel e gli anni di Stuttgart e Tübingen, Milán: Guerini, 1996, p. 93, ha detectado con razón el influjo de Lessing. Sin embargo, además de esta influencia, probablemente resuene aquí la admisión de la preferencia, consolidada en los años del Gymnasium gracias a preceptores como Hopf, por la filosofía romana y concretamente por Cicerón, sobre el pensamiento griego. Estudiando documentos de esa época, como el Diario o los Exzerpte, se puede afirmar que, a través de su detallado estudio del De Officiis y del Somnium Scipionis, Hegel recibe el ideal estoico del compromiso civil y público de la filosofía. En cambio, su estudio de la filosofía griega se concentró sobre todo en el Sobre lo sublime de (Pseudo-) Longino; de ahí que en estos escritos de finales de los años 80 se conceda una indudable primacía estética y artística a Grecia, pero que la balanza, en los terrenos de la Historia y de la filosofía política, esté mucho más equilibrada, 
o incluso algo inclinada del lado romano.

${ }^{11}$ Cfr. Ripalda, J. M., La nación dividida, México: FCE, 1978, p. 54, in nota.

${ }^{12}$ Cfr. Giardina, A., Vauchez, A., Il Mito di Roma da Carlo Magno a Mussolini, Roma-Bari: Laterza, 2000, pp. 125-126:

“all'antichitá conducevano inevitabilmente le letture dei politici, che trovavano nei personaggi e negli eventi del mondo antico il proprio linguaggio comune. Letture da adulti, naturalmente, ma soprattutto letture giovanili, che venivano abbondantemente praticate nei collegi, e che conferivano una sorta di imprinting. Non si puó negare che, come aveva ripetuto piú volte Hobbes circa un secolo e mezzo prima, dalla storia greca e romana i giovani potessero apprendere ad ammazzare i propri re. [...] Molti ebbero certamente lo stesso pensiero di Desmoulins: «con la testa infarcita di greco e latino eravamo dei repubblicani di collegio»".

${ }^{13}$ Ripalda, J. M., La nación dividida, op. cit. p. 54.

${ }^{14}$ Uno de los elementos neo-romanos que se difundió en Francia en los momentos de agitación ideológica previos e inmediatamente posteriores al 14 de julio, fue la costumbre de jurar por Bruto; pues bien, con esta denominación los revolucionarios se referían indistintamente a dos personajes ciertamente emparentados, pero muy diferentes entre sí: Lucio Junio Bruto, fundador de la República y enemigo del último rey, Tarquinio el Soberbio, y Marco Junio Bruto, el cesaricida. Los dos individuos representaban respectivamente la fundación y la defensa extrema de la República, la virtus que nunca cede ante los abusos de los tiranos, y sobre todo que pone a la patria por encima de los afectos y de los vínculos familiares (de hecho, como se sabe, Marco Junio mató no sin reparos, o por lo menos así nos lo presenta Shakespeare en el Julio César, a su propio padre, mientras que Lucio Junio hizo ajusticiar a dos de sus hijos porque habían conspirado en favor del monarca derrocado y aliado con los etruscos; este último hecho fue representado por el pintor oficial de la Revolución, David, en su famoso cuadro del Salon de 1789.

${ }^{15}$ Cfr. Hoffmeister, J., op. cit., p. 3: "Werden sich die freien Römer so zu unserer Herrschaft verstehen? Wird Brutus, wird Cassius, werden die Andern, die den edlen Cäsar töten halfen, stille dabei sein? Wird Sextus Pompejus sich zufrieden stellen lassen?".

${ }^{16}$ Cfr. Hoffmeister, J., op. cit., p. 4: “Aber ein Brutus, ein Cassius, ist weit über die Sphäre des Pöbels erhaben”.

${ }^{17}$ Cfr. ibidem: "bei dem niedrigen Pöbel ist es mit wenig Worten, etwas Getreide und öffentlichen Schauspielen geschehen".

${ }^{18}$ Cfr. Hoffmeister, J., op. cit., p. 4: "sollen wir diesen unfruchtbaren Kopf einst an der Beherrschung der Welt Teil nehmen lassen?".

${ }^{19}$ De este modo ha interpretado la Unterredung Harris, H. S., Hegel's Development, Oxford: Oxford University Press, 1972, p. 31: “Octavius [...] is clearly Hegel's hero”. Harris toma como sinceras las defensas de Lépido y Cicerón por parte del futuro emperador, y considera que las expresiones de no sometimiento a la esclavitud constituyen una muestra de "idealization of Republican freedom". Sin embargo, como se verá a continuación, las palabras de Octavio deben considerarse como una perversión de la jerga republicana.

${ }^{20}$ Cfr. Hoffmeister, J., op. cit., p. 4: "Der Blödsinn ging zuerst fort und dann der Übermut hinten nach. Was Antonius von Lepidus sagte, ist zwar gar nicht falsch, aber Antonius ist stolz, herrschsüchtig, wollüstig, grausam. Sind unsere Feinde besiegt und Lepidus bei Seite geschafft, so wird Antonius, auf seine Taten und Erfahrung stolz, mich als einen jüngeren Mann nach seiner Willkür herumführen wollen. Aber an mir wird er keinen Lepidus finden. Mein unsklavischer Nacken ist nicht gewohnt, sich unter die herabsehenden Blicken eines Beherrschers zu schmiegen. Er wird sich in den Wollüsten herum wälzen. Ich werde es lange zulassen und stilldabei sein. Aber wenn seine Leibes- und Seelenkäfte erschlafft sind und er in Verachtung steht, dann erst will ich mein Haupt emporheben, ihm mich meiner Größe zeigen und dann - - aut Caesar, aut nihil. Entweder soll er sich vor mir im Staub demütigen, oder ich werde den Tod einem schmachvollen Leben vorziehen!".

${ }^{21}$ Cfr. Schiller, F., Die Verschwörung des Fiesco zu Genua, Philipp Reclam, Stuttgart, 2006.

${ }^{22}$ Para una reconstrucción de las relaciones entre Schiller y Abel, y sobre todo la importancia de este último como figura mediadora y transmisora, en el ambiente de la Karlsschule, de las disputas entre Mendelssohn y Abbt acerca de la Bestimmung des Menschen, cfr. Macor, L. A., Il giro fangoso dell'umana destinazione. Friedrich Schiller tra l'illuminismo e il criticismo, Pisa: ETS, 2008, pp. 23-52.

${ }^{23}$ Ripalda, J. M., La nación dividida, op. cit., p. 136, in nota. El propio Hegel en una entrada del Diario del 14 de julio de 1785 anota: "Herr Professor Abel und Herr Professor Hopf beehrten unsere Gesellschaft vorgestern mit einem Besuch. Wir ging mit Ihnen (!) spazieren, wo sie uns besonders von Wien unterhielten" (Cfr. Hoffmeister, J., op. cit., p. 15). El punto de exclamación nos hace pensar en la gran admiración que el joven Hegel tenía hacia estos profesores, pues consideraba un honor y un privilegio incluso tan sólo poder pasear con ellos.

${ }^{24}$ Ripalda, J. M., La nación dividida, op. cit., p. 137, in nota.

${ }^{25}$ Schiller, F., op. cit., p. 3.

${ }^{26}$ Ripalda, J. M., La nación dividida, op. cit., p. 137.

${ }^{27}$ Cfr. Hoffmeister, J., op. cit., p. 13: "Dies mu $\beta$ ich hinzufügen, da $\beta$ er mir XVIII Bände von Shakespeare’s Shauspielen 
schon 1778 zum geschenk machte".

${ }^{28}$ Cfr. Pinkard, T., Hegel, Madrid: Acento, 2001, p. 34.

${ }^{29}$ Cfr. Rühle, V., En los laberintos del autoconocimiento: el Sturm und Drang y la Ilustración alemana, Madrid: Akal, 1997, p. 41: “el ideal del «narrador, poeta, creador» genial fue, para la generación del Sturm und Drang, Shakespeare, cuyos dramas, ya en los años sesenta, y en contra de los dramas atenidos a la preceptiva clásica (dramas que se habían petrificado en una dogmatización de la poética aristotélica), habían hecho valer Wieland y Lessing. Para los hombres del Sturm und Drang, Shakespeare fue absolutamente el ideal de genio prometeico, al que dotaron de atributos divinos. [...] Junto con las ideas de Lenz sobre el teatro, que tanto se anticipaban a su tiempo, la carta abierta de Goethe «En el día de Shakespeare» (1771) y la composición de Herder «Shakespeare» son los documentos más demostrativos de la reverencia por Shakespeare que caracterizó a los protagonistas del Sturm und Drang. La estatura colosal del genio de Shakespeare fue su ideal y la garantía de que era posible realizar sus ambiciosos sueños". Dada esta visión del autor del Julio César en la época de formación de Hegel, no sorprenden los elogios que éste le dirige en muchos lugares de los Escritos de juventud como educador del pueblo inglés. Cfr., por ejemplo, un texto de La positividad [del Espíritu del Cristianismo] en la p. 145: "los caracteres de las obras de Shakespeare, por su veracidad, causaron impresión honda en el pueblo inglés y le formaron un mundo propio de imágenes fantásticas, aparte del hecho de que muchos de esos caracteres son conocidos de la historia. Como resultado, el pueblo, con ocasión de las exposiciones de cuadros académicos, entiende perfectamente y goza con libertad de la Galería Shakespeare, en la cual compiten los mejores artistas".

${ }^{30}$ Sobre todo la comparación de César con el rayo y la mención de los robles devastados por aquél, en clara alusión a Pompeyo, es un tópos clásico de la Farsalia. Sobre estos símbolos en Lucano y su difusión como elemento recurrente de la literatura política occidental, cfr. Narducci, E., Lucano. Un'epica contro l'impero, Roma-Bari: Laterza, 2002, pp. 187 y sigs.

${ }^{31}$ Cfr. Shakespeare, W., Macbeth, Otelo y Julio César, Madrid: Edaf, 2006, p. 209: "Bruto: «mis antepasados arrojaron de las calles de Roma a Tarquinio cuando era llamado Rey»".

${ }^{32}$ Cfr. Hoffmeister, J., op. cit., p. 45: "noch in unsern Tagen weissagt man aus einem Kometen das Lebensende eines Monarchen". El tema de los cometas está lleno de elementos de reflexión, en comparación con otras obras hegelianas. Ya en Über die Religion se encontraba una referencia a estos cuerpos celestes, con una clara polémica polémica anticristiana y más en general dentro del clima ilustrado de lucha contra la superstición; cfr. Hoffmeister, J., op. cit., p. 45: "ein aberglaubicher Grieche ging darin nicht über den Weg, wenn ein Wiesel an ihm vorbeigesprungen war; er fragte einen Zeichendeuter um Rat, wenn eine Maus seinen Mehlsack angenagt hatte". Sin embargo, en la reflexión cosmológica hegeliana, los cometas siempre serán el ejemplo de la libertad meramente formal, azarosa, que depende de un elemento externo y que no tiene en sí mismo la causa su movimiento (Cfr. Erle, G., «Logos e natura: aspetti della critica di Hegel al dover essere», Fenomenologia e Società, n. 2/2009, esp. las pp. 97-99). No es descabellado pensar que estas consideraciones cosmológicas, que se encuentran in nuce ya en el De Orbitis Planetarum, tengan una base precisamente clásica, es decir, la idea ampliamente extendida, como estamos viendo, de que son acontecimientos extrínsecos, y en concreto grandes eventos históricos, los que provocan la aparición de los cometas.

${ }^{33}$ Shakespeare, W., op. cit., p. 218.

${ }^{34}$ Shakespeare, W., op. cit., pp. 243-244. Compárese el "espíritu estéril" de Lépido con el apelativo "cabeza estéril" que encontrábamos en la Unterredung.

${ }^{35}$ Ibidem.

${ }^{36}$ Ibidem.

${ }^{37}$ Shakespeare, W., op. cit., p. 268.

${ }^{38}$ Es precisamente de Shakespeare de quien, muy probablemente, Hegel retoma una temática, la de "la alianza sin sellos ni promesas", que se encuentra en los versos centrales del gran poema Eleusis, escrito al final de la época de Berna y en honor a Hölderlin. Si en esta expresión D’Hondt, Hegel secreto, Buenos Aires: Corregidor, 1976, pp. 217 y sigs. ve rastros del Bund propio de la francmasonería, es bastante más razonable reconocer en ella una reminiscencia de ese republicanismo que emana de las palabras de Bruto en el Julio César shakespeariano: cfr. Shakespeare, W., op. cit., p. 211: "No. Nada de juramento [...] ¿Qué mejor lazo que el de secretos romanos que han dado su palabra y que no la burlarán? ¿Ni qué otro juramento que el compromiso de la honradez con la honradez para realizar esto o sucumbir por ello? Juren los sacerdotes y los cobardes, y los hombres recelosos, decrépitos, corrompidos, y las almas que en sus padecimientos buscan sendas torcidas. Juren en pro de malas causas aquellos miserables que inspiran dudas a los hombres; pero no manchéis la clara virtud de nuestra empresa, ni la inquebrantable altivez de nuestros ánimos con el pensamiento de que nuestra causa o su ejecución necesitaban ser juradas; siendo así que cada gota de la sangre que cada romano lleva, y lleva noblemente, sería culpable de bastardía si él quebrantara la más leve parte de promesa alguna que hubiese hecho". Sobre la presencia de esta alianza en Eleusis, cfr. mi «De la cuádruple fuga de Eleusis», Despalabro. Ensayos de Humanidades, n. III, 2009. 
${ }^{39}$ D’Hondt, J., Hegel, Barcelona: Tusquets, 2002, p. 55. Cfr. Pinkard, T., op. cit., p. 60: “en lugar de ceñirse a lo que su carrera requería, se enfrascó por su cuenta en otras lecturas y en particular en las obras de Jean-Jacques Rousseau. Al recordarlo años después, muchos de sus amigos universitarios lo evocaban en aquélla época como un ardiente partidario de Rousseau (Hegel y sus compañeros de clase habían escrito, por ejemplo, cada uno en el álbum del otro 'Viva Jean-Jacques')".

${ }^{40}$ Cfr. Hegel, G. W. F., Frühe Exzerpte, in Gesammelte Werke, 3, Hamburgo: Felix Meiner Verlag, 1991, p. 6.

${ }^{41}$ Pinkard, T., op. cit., p. 42.

${ }^{42}$ Cfr. Ripalda, J. M., La nación dividida, op. cit., pp. 138-140, in nota: "la pérdida del extracto que Hegel hizo de las Confesiones nos priva de esta posibilidad de comprobar su impacto preciso en él [...]. Hegel no pudo haber leído en Stuttgart sino los primeros seis libros de las Confesiones; los seis siguientes, más ricos -sobre todo el noveno- en formulaciones sintéticas orientadoras, aparecieron en 1789."

${ }^{43}$ Cfr. Ibidem.

${ }^{44}$ Cfr. Tassi, A., op. cit., p. 70: "il richiamo a Herder e alla sua tematica storica, sviluppata in riferimento dialettico con Montesquieu e in particolare con l'ultimo capitolo del Contrat Social, del 1764, é implicito".

${ }^{45}$ Cfr, Duque, F., Historia de la filosofía moderna. La era de la crítica, Madrid: Akal, 1998, p. 323: "las guías eran aquí [en Stuttgart] Herder, Rousseau y Goethe".

${ }^{46}$ Cfr. por ejemplo, Rousseau, J.-J., Del Contrato Social. Discursos., Madrid: Alianza, 2001, p. 113.

${ }^{47}$ Rousseau, J.-J., op. cit., p. 201.

${ }^{48}$ Cit. ibidem, in nota.

${ }^{49}$ Cfr. Rousseau, J.-J., op. cit., p. 182: “Sócrates había comenzado en Atenas, el viejo Catón continuó enfureciéndose contra aquellos griegos artificiosos y sutiles que seducían la virtud y ablandaban el valor de sus conciudadadanos. Pero las ciencias, las artes y la dialéctica prevalecieron aún: Roma se llenó de filósofos y oradores; la disciplina militar se descuidó, se despreció la agricultura, se abrazaron las sectas y se olvidó la patria. A los nombres sagrados de libertad, de desinterés y de obediencia a las leyes sucedieron los nombres de Epicuro, Zenón y Arcesilao. Desde que los doctos empezaron a aparecer entre nosotros, decían sus propios filósofos, las gentes de bien se han eclipsado. Hasta entonces los romanos se habían contentado con practicar la virtud; todo se perdió cuando empezaron a estudiarla" (Tr. modif.).

${ }^{50}$ Ibidem.

${ }^{51}$ Rousseau, J.-J., op. cit., p. 179.

52 Ibidem.

${ }^{53}$ Rousseau, J.-J., op. cit., p. 77.

${ }^{54}$ Cfr. Ripalda, J. M., El fin del clasicismo. A vueltas con Hegel, Madrid: Trotta, 1992, p. 150: "Si, como hemos visto, también Robespierre explicó su acción ideológicamente, el aire de familia entre él y Hegel no hace sino aumentar con el detalle sus ideas. Puntos fundamentales en la concepción política del jacobino son: la virtud como guía de la política. Esta virtud, que, de la mano de Rousseau, pretende enlazar con la Roma republicana de los Horacios, Scevola, Graco, es asimismo fuerza heroica, virtus. La imagen política que sustenta la transposición clásica al presente es la de un pueblo de pequeños propietarios libres, alianza de artesanos y campesinos, repetición moderna de la plebe romana y del ateniense (o más bien del «espartano») libre. También los escritos juveniles de Hegel, como muchos otros de la generación prerromántica [...] se hallan repletos de la invocación a la «virtud republicana» bajo modelo clásico e inspiración rousseauniana". 